\title{
THE PREPARATION AND CHARACTERIZATION OF COPPER-CONTAINING THIN FILMS PREPARED BY THE SOL-GEL METHOD ON VARIOUS GLASSES
}

\author{
"PETR VAŘÁK, BLANKA ŠVECOVÁ, DIANA HORKAVCOVÁ*, SOŇA VYTYKÁČOVÁ \\ Department of Inorganic Chemistry, University of Chemistry and Technology Prague, \\ Technicka 5, 16628 Prague, Czech Republic \\ *Department of Glass and Ceramics, University of Chemistry and Technology Prague, \\ Technicka 5, 16628 Prague, Czech Republic \\ "E-mail: Petr.Varak@vscht.cz
}

Submitted December 1, 2016; accepted accepted January 31, 2017

\begin{abstract}
Keywords: Silicate glasses, Copper, Sol-gel method, Dip-coating
Copper-containing glasses are promising materials for photonic applications. The sol-gel method has been verified as a feasible way to prepare thin glassy films containing copper (I) for utilization in active photonic devices. The aim of this paper was to deposit copper-containing thin films on various types of silicate glasses and test them with regard to their quality, structure and the optical properties of the prepared films and the oxidation state of the embedded copper. Two types of sols consisting of $\mathrm{CuCl}$, TEOS, $\mathrm{HCl}$, ethanol, $\mathrm{H}_{2} \mathrm{O}$ and the surfactants Triton X-100 or PEG-400 were used to create functional layers. Both sols were deposited on substrates by the dip-coating technique. The functional layer was covered with another sol not containing copper in order to create a protective layer above the optical one. The films were annealed at two different temperatures to change the oxidation state of the embedded copper. The coated samples were characterized by SEM, XRD and absorption and photoluminescence spectroscopy. We have proven that it is possible to form quality films on all types of glasses used.
\end{abstract}

\section{INTRODUCTION}

Copper-containing glasses have been known for hundreds of years because of their beautiful color, but they have lately become promising candidates for photonics applications. Copper can be present in glass in three stable oxidation states, each of which gives glass unique properties resulting in the different utilization of the glasses. $\mathrm{Cu}(0)$ nanoparticles introduce a ruby-red coloration of glass due to absorption with the maximum between 550 and $570 \mathrm{~nm}$, a consequence of surface plasmon resonance, which gives such glass nonlinear optical properties [1-4]. Glasses containing copper in oxidation states, $\mathrm{Cu}(\mathrm{I})$ or $\mathrm{Cu}(\mathrm{II})$, create planar optical waveguides, which can be utilized in both passive (divalent copper) and active (monovalent copper) devices $[5,6]$.

One of the ways to create the demanded optical layers is the use of the sol-gel method, which is feasible for the fabrication of thin films with high chemical purity and specific properties, such as antibacterial [7], or in our case optical $[8,9]$. Our research team has already developed a new approach based on the use of microscope glass, copper (I) chloride and the dip-coating technique [10]. It has also been shown that surfactants play an important role in the creation of films of demanded quality. In this paper, we have developed this approach further and tested it on other types of silicate glasses. Besides microscope glass, we have chosen glasses BK7 and GIL49, which were previously used for the creation of optical layers by ion exchange $[5,11]$ or ion implantation [12-18]. Thin films were deposited on these three substrates by the same approach as that used in [10], with the exception of using exclusively PEG-400 or Triton X-100 as surfactants as these had been proven to have the best effect on the adhesion of the layers to the substrates. The optical layers were coated with a copperfree layer in order to protect the optical layer from damaging and the oxidation of copper. The final films were heated at two different temperatures to observe its effect on the oxidation state of copper.

\section{EXPERIMENTAL}

Three types of silicate glasses were used as substrates - common microscope glass, BK7 and GIL49 (see Table 1). Microscope glass had slightly different composition on both sides as one side contained trace amounts of tin. The glass slides used were about $20 \mathrm{~mm}$ long, $10 \mathrm{~mm}$ wide and $1 \mathrm{~mm}$ thick. Prior to the experiment, the slides were thoroughly washed with detergents, demineralized water, ethanol and isopropanol in ultrasound. 
Vařák P., Švecová B., Horkavcová D., Vytykáčová S.

Table 1. The composition of the substrates used (wt. \%)

\begin{tabular}{|c|c|c|c|c|}
\hline \multirow{2}{*}{ Components } & \multicolumn{2}{|c|}{ Microscope glass } & \multirow{2}{*}{ BK7 } & \multirow{2}{*}{ GIL 49} \\
\hline & Side 1 & Side 2 & & \\
\hline $\mathrm{Na}_{2} \mathrm{O}$ & 14.2 & 14.1 & 8.8 & 14.0 \\
\hline $\mathrm{K}_{2} \mathrm{O}$ & 0.3 & 0.3 & 8.0 & 0.4 \\
\hline $\mathrm{MgO}$ & 4.3 & 4.2 & - & 4.4 \\
\hline $\mathrm{CaO}$ & 8.6 & 8.8 & 0.1 & 6.3 \\
\hline $\mathrm{B}_{2} \mathrm{O}_{3}$ & - & - & 12.0 & - \\
\hline $\mathrm{Al}_{2} \mathrm{O}_{3}$ & 0.7 & 0.7 & - & 1.3 \\
\hline $\mathrm{As}_{2} \mathrm{O}_{3}$ & - & - & 0.9 & - \\
\hline $\mathrm{SiO}_{2}$ & 71.7 & 71.1 & 67.7 & 73.7 \\
\hline $\mathrm{BaO}$ & - & - & 2,5 & - \\
\hline $\mathrm{SO}_{3}$ & 0.2 & - & - & - \\
\hline $\mathrm{SnO}_{2}$ & - & 0.6 & - & - \\
\hline Other traces & $\mathrm{TiO}_{2}, \mathrm{Fe}_{2} \mathrm{O}_{3}$ & $\begin{array}{c}\mathrm{TiO}_{2} \\
\mathrm{Fe}_{2} \mathrm{O}_{3}, \mathrm{~S}\end{array}$ & - & $\begin{array}{c}\mathrm{Fe}_{2} \mathrm{O}_{3} \\
\mathrm{Cl}\end{array}$ \\
\hline
\end{tabular}

Two types of surfactants were used for the preparation of sols, Triton X-100 and PEG-400. To avoid confusion, the films prepared from sol containing Triton $\mathrm{X}-100$ will hereinafter be designated as SCT and the films prepared from sol containing PEG-100 will be labeled as SCP.

The basic component of each sol was tetraethyl orthosilicate (TEOS, $10 \mathrm{ml}$ ); the other components were hydrochloric acid (35\%, 20 drops), ethanol (15 ml), surfactant (PEG-400 or Triton X-100, $15 \mathrm{ml}$ ) and water $(1 \mathrm{ml})$. Functional sols contained copper in the form of copper (I) chloride $(0.5 \mathrm{~g})$, while protective sols were copper-free. The sols were prepared by stirring the components at room temperature for $30 \mathrm{~min}$ (functional sols) or $90 \mathrm{~min}$ (protective sols). Afterward, the sols aged for 7 days at room temperature in darkness.

Glass slides were dipped (at the rate of $20 \mathrm{~cm} / \mathrm{min}$ ) into a particular sol containing copper and pulled out (at the rate of $6 \mathrm{~cm} / \mathrm{min}$ ) with a dwell time of $30 \mathrm{~s}$. The slides were left to dry and the process was repeated for a copper-free sol with a dwell time of $10 \mathrm{~s}$. The samples were annealed for $120 \mathrm{~min}$ at $400^{\circ} \mathrm{C}$ and subsequently re-annealed for $60 \mathrm{~min}$ at $600^{\circ} \mathrm{C}$.

The surface of the films was characterized by scanning electron microscopy, using HITACHI S-4700. The samples were coated with an Au-Pd layer and the accelerating potential was set at $15 \mathrm{kV}$. XRD spectra were measured by a BRUKER D2 Phaser. The absorption spectra of the samples were taken in the region of 300-800 nm by VARIAN Cary 50. Photoluminescence spectra were taken in the region of $300-900 \mathrm{~nm}$ by HITACHI F-450, the excitation wavelength was set at $270 \mathrm{~nm}$.

\section{RESULTS}

The quality and structure of the films

The quality of the prepared films was characterized by scanning electron microscopy. As can be seen in Figs. 1 and 2, the films prepared contained defects and pores of various sizes. However, most of the films were overall smooth and homogeneous. Fig. 1a shows an SCT film deposited on microscope glass and annealed at $400{ }^{\circ} \mathrm{C}$. The film was homogeneous and crack-free on both sides of glass (with and without tin content). Only small defects (e.g. pores) with the size of several micrometers were noticeable. Re-annealing at $600{ }^{\circ} \mathrm{C}$ had no significant impact on the quality of the film (see Fig. 1b).

As arises from Fig. $2 \mathrm{a}$, the annealed $\left(400^{\circ} \mathrm{C}\right) \mathrm{SCP}$ film deposited on microscope glass did not differ much from the SCT film. After re-annealing, however, small particles could be seen on the surface (see Fig. 2b).

The films prepared on glasses GIL49 and BK7 had as high quality as those deposited on microscope glass (not shown). Annealed $\left(400^{\circ} \mathrm{C}\right)$ films were mostly homogeneous and crack-free, only the SCP film depo-

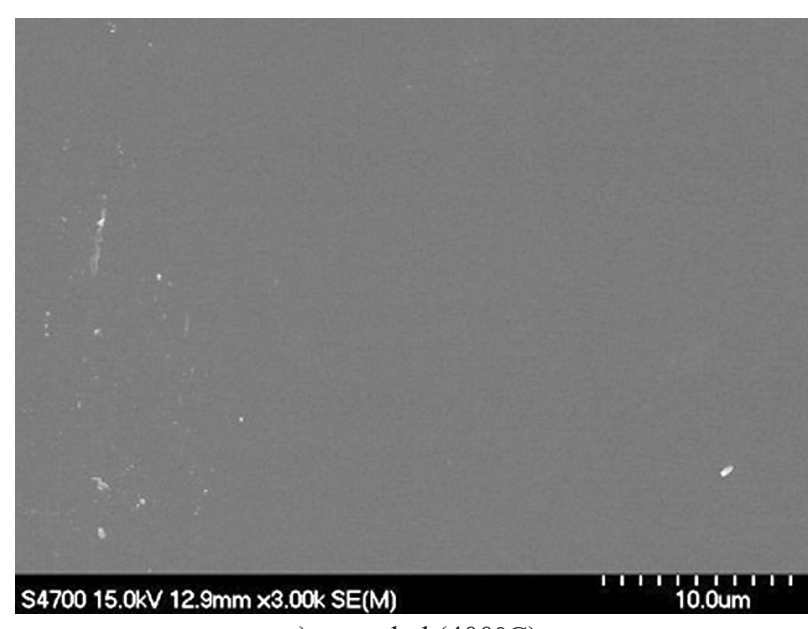

a) annealed $\left(400^{\circ} \mathrm{C}\right)$

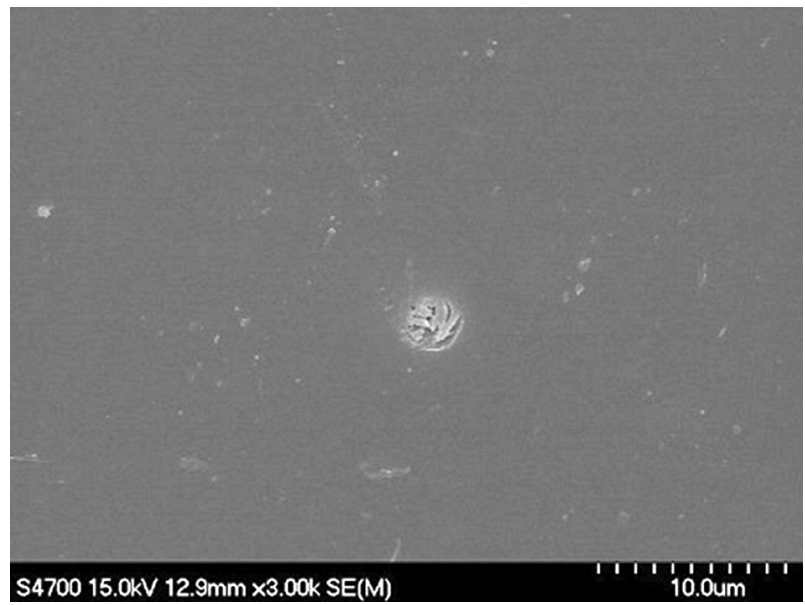

b) re-annealed $\left(600^{\circ} \mathrm{C}\right)$

Figure 1. SCT films deposited on microscope glass, a) annealed $\left(400^{\circ} \mathrm{C}\right)$, b) re-annealed $\left(600^{\circ} \mathrm{C}\right)$. 
sited on glass GIL49 contained a slightly higher number of defects than other films. However, subsequent re-annealing resulted in significant damage and cracking of both SCT and SCP films deposited on glass BK7, as well as the SCP film prepared on glass GIL49.

Scanning electron microscopy was also used to determine the thickness of the films from their cross section. In Fig. 3, we can clearly see the interface between the film deposited by the sol-gel method and the glass. The annealed SCT film (i.e., copper containing layer together with copper-free layer) prepared on microscope glass was about 700-800 nm thick. On the other hand, the annealed SCP film had slightly lower thickness, of about $600-700 \mathrm{~nm}$, although it was prepared by the same procedure as the SCT film.

The XRD spectra of the films deposited on microscope glass can be seen in Fig. 4. Since no peak implying the presence of a crystal phase is present in the spectra, the structure of the films is fully amorphous.

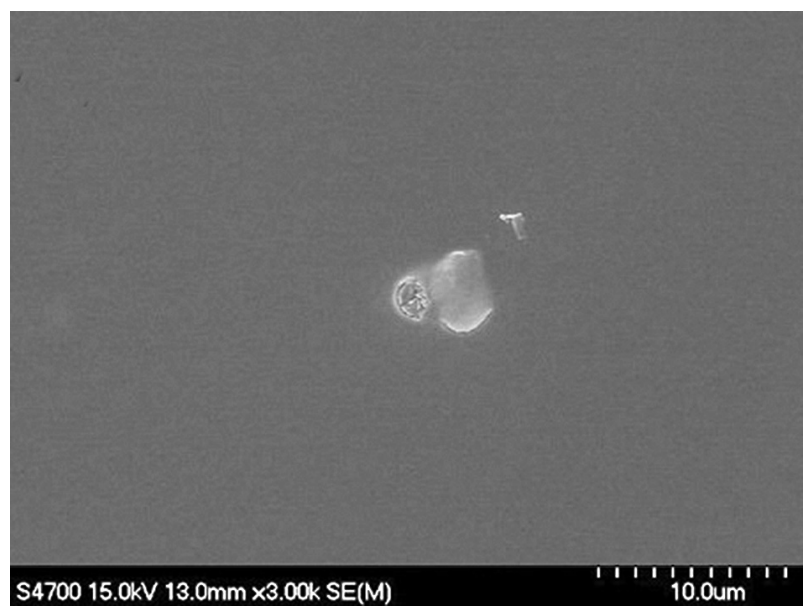

a) annealed $\left(400^{\circ} \mathrm{C}\right)$
Absorption spectra

Absorption spectra in the UV/VIS region may provide information on two oxidation states of copper. Copper (II) ions show an absorption band with its maximum around $700 \mathrm{~nm}$, while copper $(0)$ nanoparticles show an absorption band with its maximum around $550 \mathrm{~nm}$. When analyzing the absorption spectra of samples prepared by the sol-gel method, the effect of thin-film interference must be taken into account. Thinfilm interference occurs when the refractive index of the prepared film is different from that of the original substrate and the thickness of the film is comparable to the wavelength of the light (it is valid for films with thickness up to five times the wavelength; for visible light, this means about 4-5 $\mu \mathrm{m}$ [19]). Depending on the thickness of the film and the wavelength of the light, the intensity of the light either weakens or strengthens and characteristic coloration appears on the film. As for the absorption spectra, thin-film interference causes

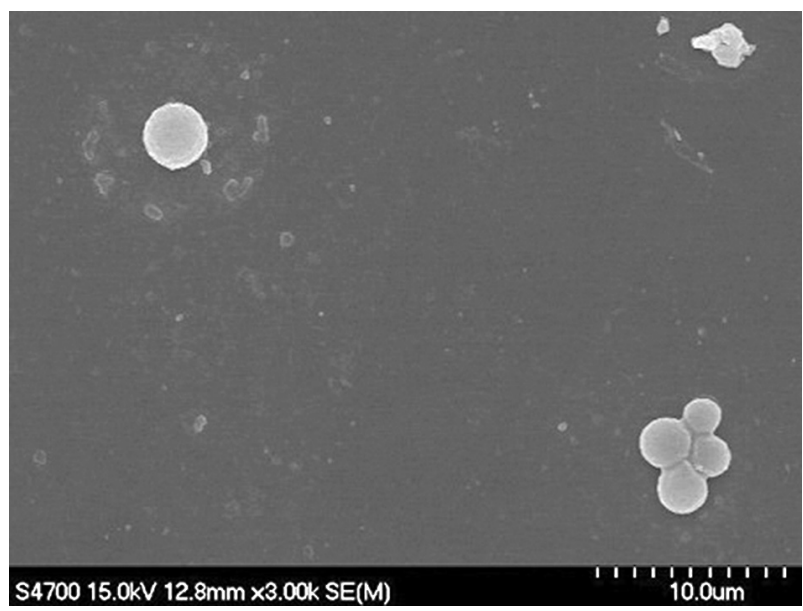

b) re-annealed $\left(600^{\circ} \mathrm{C}\right)$

Figure 2. SCP films deposited on microscope glass, a) annealed $\left(400^{\circ} \mathrm{C}\right)$, b) re-annealed $\left(600^{\circ} \mathrm{C}\right)$.

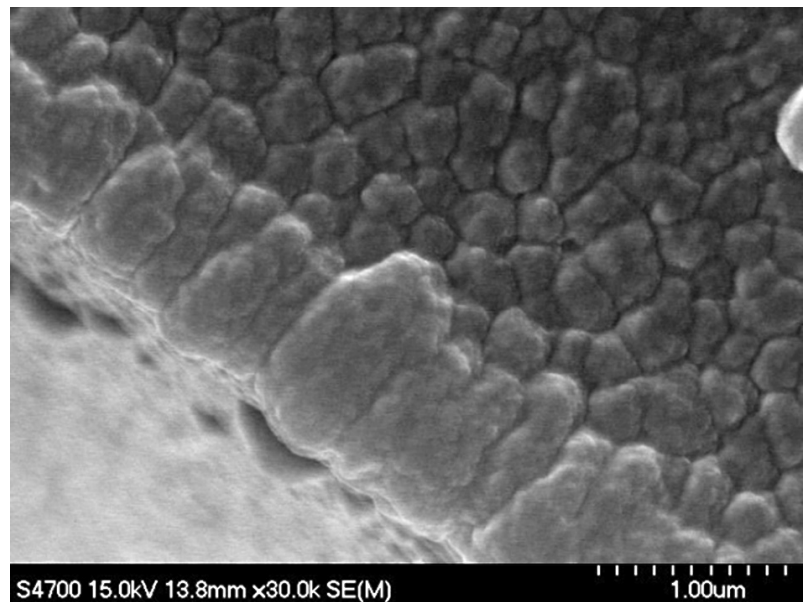

a) SCT



b) $\mathrm{SCP}$

Figure 3. The cross section of the annealed films on microscope glass, a) SCT and b) SCP films. 
Vařák P., Švecová B., Horkavcová D., Vytykáčová S.

typical "waves" in the spectra, creating one or multiple absorption maxima [19]. The absorption spectra of the SCT films deposited on microscope glass are visible in Fig. 5a. Both annealed and re-annealed samples showed a wide absorption band with the maximum between 700 and $800 \mathrm{~nm}$, which can be attributed to thin-film

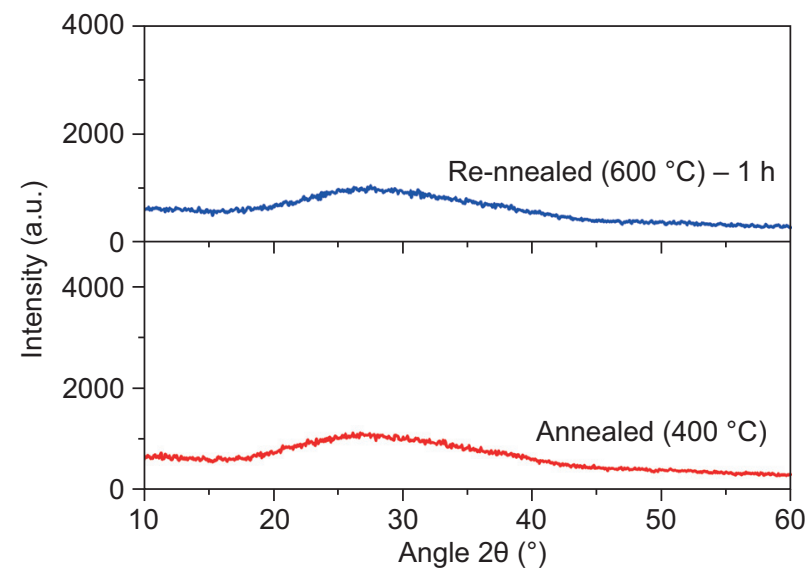

a) SCT interference. Interference is clearly visible also in the absorption spectra of the annealed SCP film shown in Fig. 5b.

The absorption spectra of the SCT films prepared on glasses GIL49 and BK7 manifested neither the presence of copper (II) ions and metallic copper nanoparticles

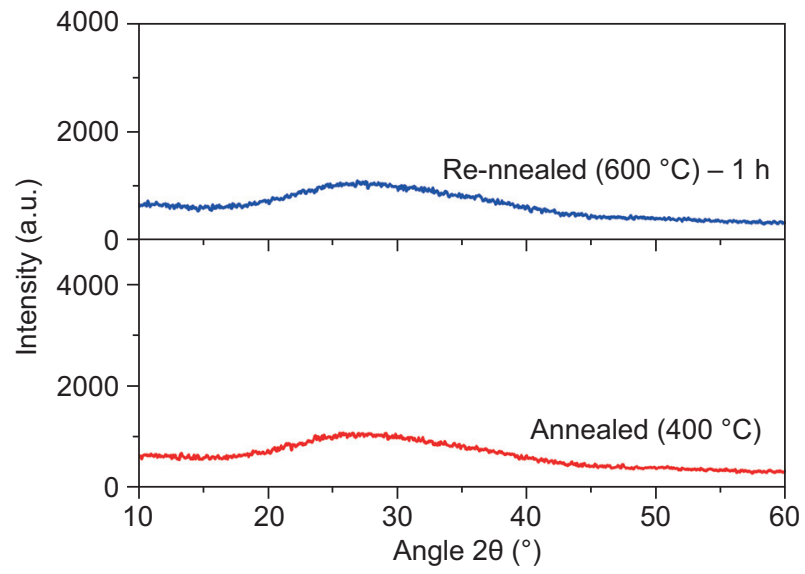

b) SCP

Figure 4. The XRD spectra of the films deposited on microscope glass, a) SCT and b) SCP films.

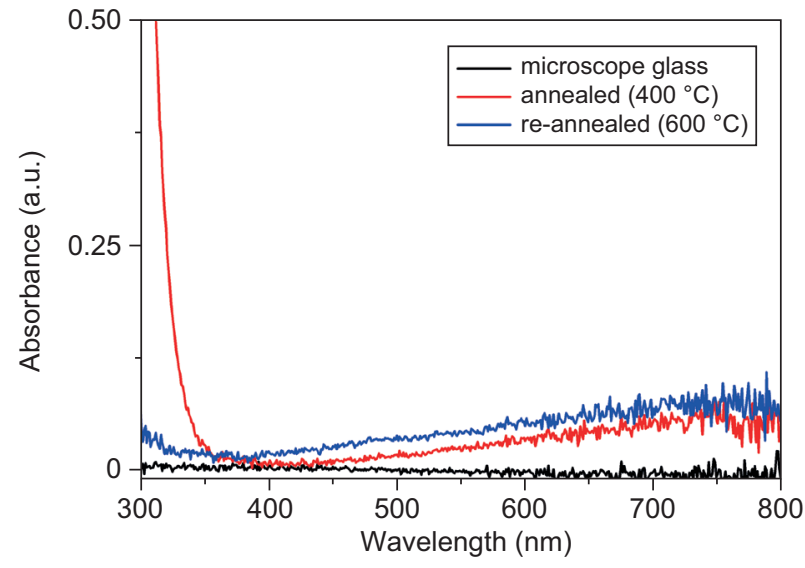

a) SCT

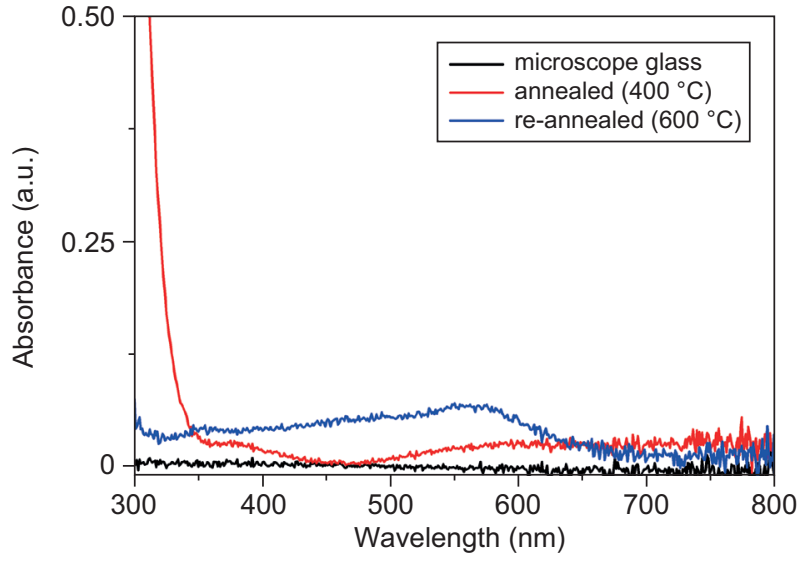

b) $\mathrm{SCP}$

Figure 5. The absorption spectra of the films deposited on microscope glass, a) SCT and b) SCP films.

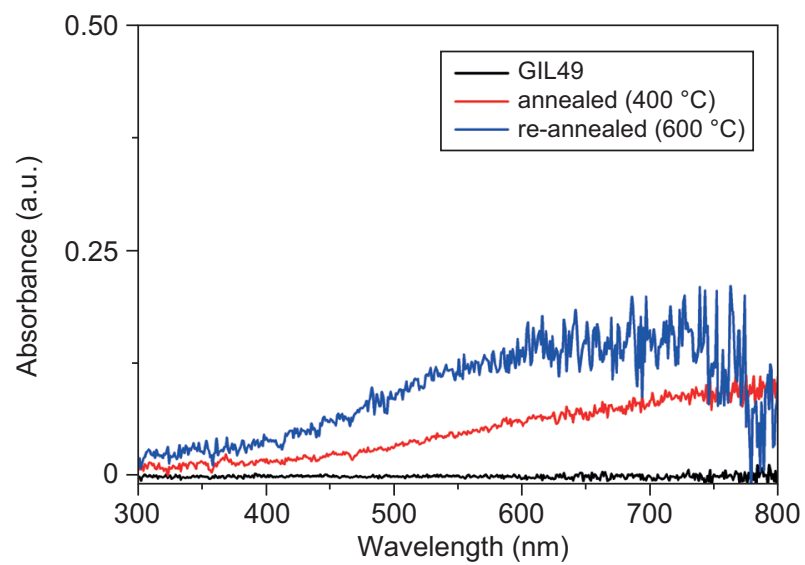

a) GIL49

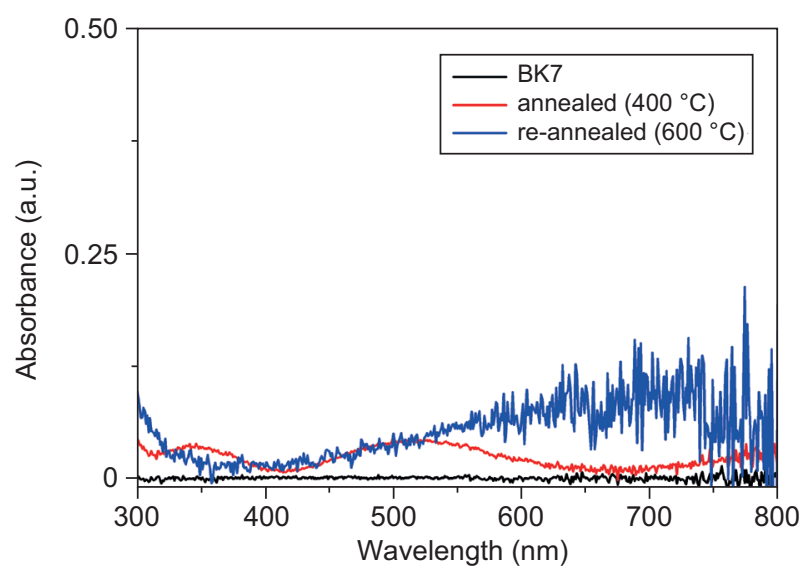

b) BK7

Figure 6. The absorption spectra of the SCP films deposited on glasses a) GIL49 and b) BK7. 
nor thin-film interference (not shown). In the spectra of both the annealed and re-annealed SCP films deposited on glass GIL49 (Fig. 6a), however, we can see a wide absorption band that can be attributed to thin-film interference. In the case of the re-annealed sample, we can observe a significant decrease in the quality of the spectra close to higher wavelengths caused by a damage to the film during re-annealing.

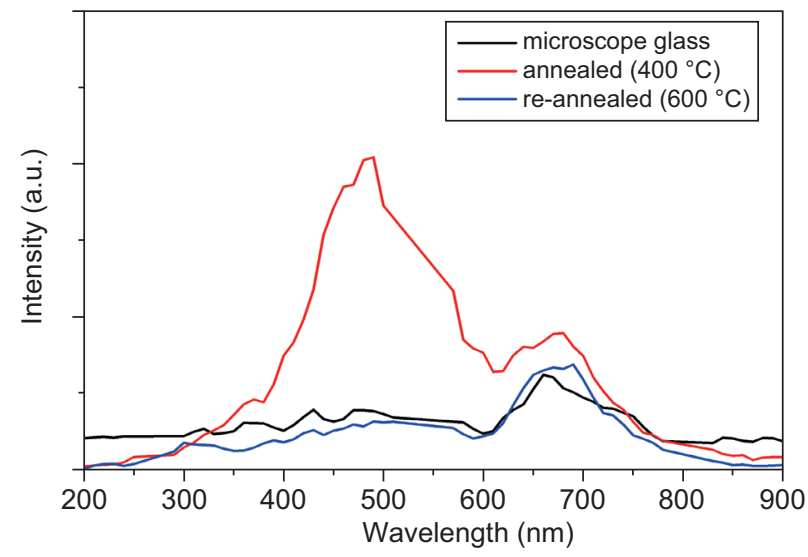

a) SCT

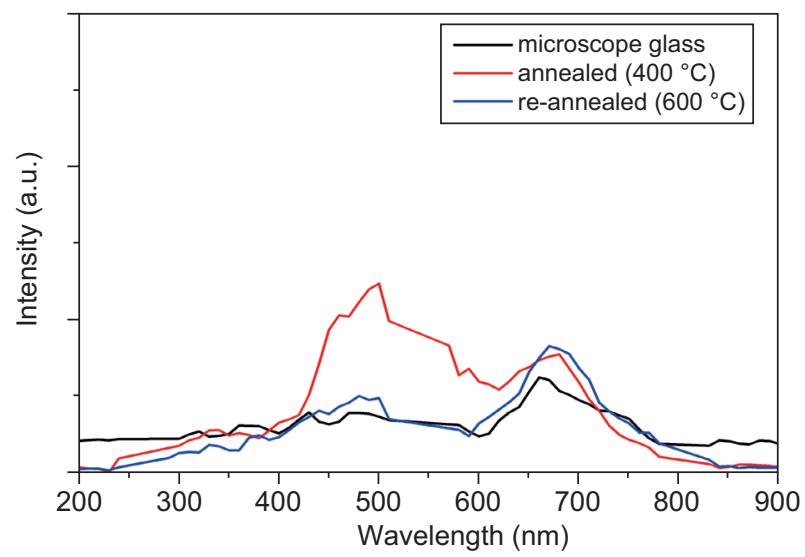

b) SCP

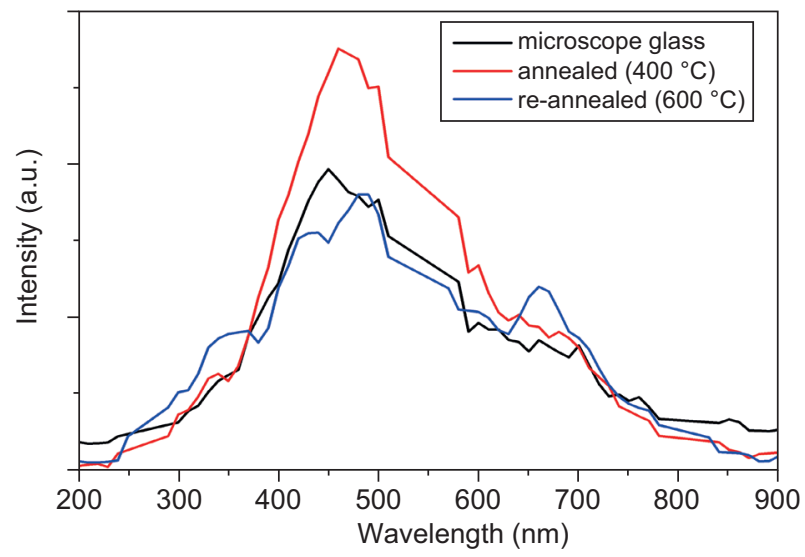

c) SCP

Figure 7. The emission spectra of the films deposited on microscope glass, a) SCT film (the side without tin), b) SCP film (the side without tin), c) SCP film (the side with tin content), excitation wavelength $=270 \mathrm{~nm}$.
Similarly to the SCP films on glass GIL49, thin-film interference is clearly present in the absorption spectra of the SCP films deposited on glass BK7 (Fig. 6b), causing two maxima (350 and $500 \mathrm{~nm}$ ) in the spectrum of the annealed sample and one maximum $(700 \mathrm{~nm})$ in the spectrum of the re-annealed sample. A significant decrease of the spectral quality in the case of the reannealed sample can also be observed close to high wavelengths.

\section{Emission spectra}

Information about the copper (I) oxidation state can be found in photoluminescence spectra in the UV/ VIS region. The emission spectra of both SCT and SCP annealed films deposited on microscope glass (the side without tin content) showed an emission band with the maximum around $490 \mathrm{~nm}$, which can be attributed to $\mathrm{Cu}^{+}$ions in tetragonal surroundings (see Figs. 7a and b). Re-annealing led to the disappearance of these bands, suggesting the oxidation of copper to $\mathrm{Cu}$ (II) oxidation state, which does not display photoluminescence in the UV/VIS region.

The emission spectra of the films deposited on the other side of microscope glass (with tin content) showed similar behavior. As arises from Fig. 7c, this side of the glass itself shows photoluminescence in the UV/VIS region. When the thin film was deposited and annealed, the emission band with the maximum around $490 \mathrm{~nm}$ was amplified, which can also be attributed to $\mathrm{Cu}^{+}$ions. After re-annealing, the intensity of emission returned to the state before the film deposition.

The emission spectra of the films prepared on glass GIL49 are shown in Fig. 8. The amplification of the emission band of the glass can be observed after annealing and re-annealing. Due to the width of these bands and the fact that re-annealing led to a further increase in the intensity, the changes in the emission spectra are more likely to have been caused by changes in the glass structure during annealing and re-annealing.

The emission spectra of the films prepared on glass BK7 showed similar behavior as those deposited on glass GIL49, and the changes of the emission band intensities are likely to have had the same cause (not shown).

\section{DISCUSSION}

The results have shown that our approach to the sol-gel method, specifically the dip-coating technique, is a suitable way to prepare thin glassy films containing copper, which is present mainly as $\mathrm{Cu}^{+}$or $\mathrm{Cu}^{2+}$ ions. Photoluminescence spectroscopy confirmed the presence of $\mathrm{Cu}^{+}$ions particularly in films deposited on microscope glass. $\mathrm{Cu}^{+}$ions were probably present in films deposited on all of the glass substrates, but in the case of glasses GIL49 and BK7, the photoluminescence of 


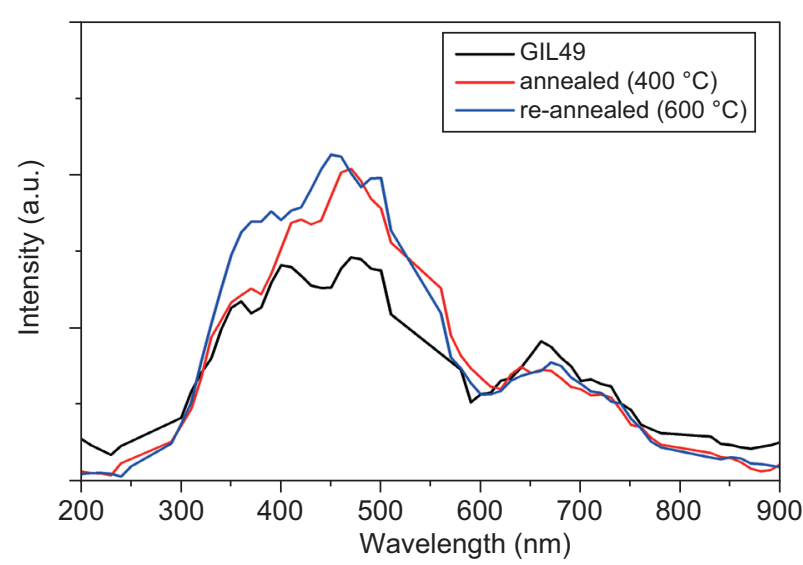

a) SCT

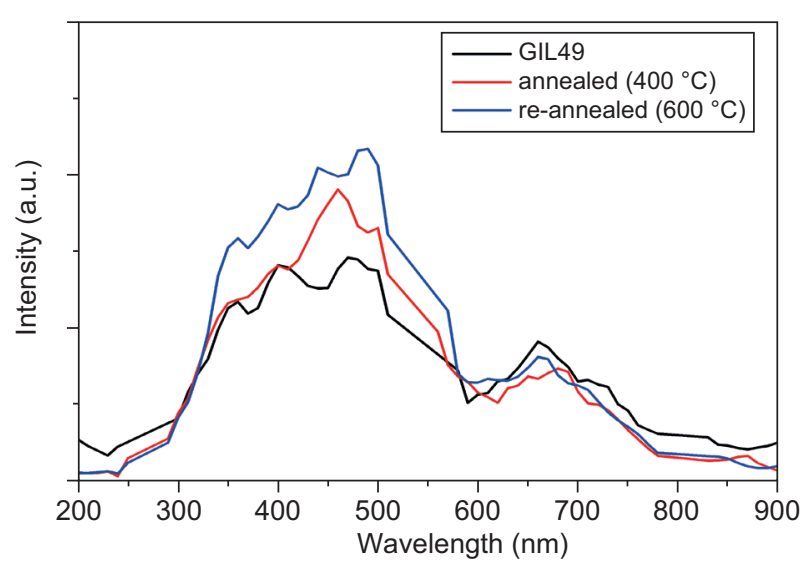

b) SCP

Figure 8. The emission spectra of the films deposited on glass GIL49, a) SCT and b) SCP films, excitation wavelength $=270 \mathrm{~nm}$

$\mathrm{Cu}^{+}$ions was hidden due to the strong emission of the substrates. In order to exceed the emission of those substrates themselves, it is necessary to introduce a higher concentration of copper into the optical layer (as was observed for glass GIL49 and ion exchange in [5]).

Re-annealing of the films at $600^{\circ} \mathrm{C}$ was expected to cause the migration of copper into the glass substrate or a change of the oxidation state of copper as was already observed in the case of similar glasses doped with a different method or different ions heated at the same temperature $[12,17]$. The oxidation of copper was manifested by the disappearance of a copper (I) emission band in the emission spectra of films prepared on microscope glass. Moreover, re-annealing had very little effect on the quality of the films deposited on this glass. On the contrary, re-annealing significantly affected the films prepared on glasses BK7 or GIL49 as cracks and pores were clearly visible in their surface. This damage was probably caused by exceeding the transformation temperature of the glasses; even the slight deformation of the substrate caused by that subsequently led to the cracking of the deposited film.

Changes in the films after re-annealing were also evident in the absorption spectra because the interference pattern observed in the absorption spectra provides information on film thickness. As the thickness decreased, so did the number of the maxima in the absorption spectra. This phenomenon was most evident in the case of the SCP film deposited on glass BK7, where the number of the maxima decreased from two to one after re-annealing due to the incineration of organic residuals and further densification and contraction of the film.

As follows from our results, the main factor for the preparation of quality films is the cleanness and smoothness of the substrate surface rather than substrate composition. Based on SEM photographs of individual film surfaces, it is safe to conclude that homogeneous and crack-free films were successfully deposited on all types of substrates. Distinct differences could not be observed even in the case of the films prepared by different surfactants. However, surfactants may affect the film thickness, as Triton X-100 produces a slightly thicker film than PEG-400. The effect of glass structure and composition is evident only after re-annealing at a higher temperature, when the glass transformation temperature plays an important role.

\section{CONCLUSION}

The sol-gel method, namely the dip-coating technique, was successfully used for the preparation of thin glassy films containing copper on three different glass substrates. Two different surfactants (Triton X-100 and PEG-400) were used, both of which provided homogeneous and crack-free films. The effect of glass structure and composition was evident only after reannealing at a higher temperature, when the glass transformation temperature plays an important role. The best results were obtained using microscope glass as a substrate. The created films showed photoluminescence in the blue-green region due to the presence of copper (I) ions in tetragonal surroundings. Re-annealing at a higher temperature $\left(600{ }^{\circ} \mathrm{C}\right)$ had no significant impact on the quality of the films prepared on this glass but led to the oxidation of copper.

\section{Acknowledgements}

The research has been supported by project No. P108/12/G108 and specific university research (MSMT 20-SVV/2016). Parts of this research have been implemented at the CANAM (Center of Accelerators and Nuclear Analytical Methods LM 2015056). 


\section{REFERENCES}

1. Ghosh B., Chakraborty P., Mohapatra S., Kurian P. A., Vijayan C., Deshmukh P. C., Mazzoldi P. (2007): Linear and nonlinear optical absorption in copper nanoclusterglass composites. Material Letters, 61, 4512-4515. doi:10.1016/j.matlet.2007.02.065

2. Ghosh B., Chakraborty P., Singh B. P., Kundu T. (2009): Enhanced nonlinear optical responses in metal-glass nanocompozites. Applied Surface Science, 256, 389-394. doi:10.1016/j.apsusc.2009.05.093

3. Wang Y. H., Wang Y. M., Lu J. D., Ji L. L., Zang R. G., Wang R. W. (2010): Nonlinear optical properties of $\mathrm{Cu}$ nanoclusters by ion implantation in silicate glasses. Optics Communications, 283, 486-489. doi:10.1016/j.optcom.2009.10.035

4. Stepanov A. L., Galyautdinov M. F., Evlyukhin A. B., Nuzhdin V. I., Valeev V. F., Osin Y. N., Evlyukhin E. A., Kiyan R., Kavetsky T. S., Chichkov B. N. (2013): Synthesis of periodic plasmonic microstructures witch copper nanoparticles in silica glass by low-energy ion implantation. Applied Physics A, 111, 261-264. doi:10.1007/s00339-012-7474-5

5. Nebolova P., Spirkova J., Perina V., Jirka I., Mach K., Kuncova G. (2001): A study of the preparation and properties of copper containing optical planar glass waveguides. Solid State Ionics, 141-142, 609-615. doi:10.1016/S0167-2738(01)00776-7

6. Spirkova J., Tresnakova P., Mika M. (2004): Optical waveguides fabricated by transition element ions exchange in some commercial and special optical glasses. Optical materials, 25, 101-107. doi:10.1016/S0925-3467 (03)00257-X

7. Akhavan O., Ghaderi E. (2010): $\mathrm{Cu}$ and $\mathrm{CuO}$ nanoparticles immobilized by silica thin films as antibacterial materials and photocatalysts. Surface and Coatings Technology, 205, 219-223. doi:10.1016/j.surfcoat.2010.06.036

8. Ray S. C. (2001): Preparation of copper oxide thin film by the sol-gel-like dip technique and study of their structural and optical properties. Solar Energy Materials and Solar Cells, 68, 307-312. doi:10.1016/S0927-0248(00)00364-0

9. Vives S., Meunier C. (2013): Optical properties of copper modified sol-gel $\mathrm{SiO}_{2}$ thin films. Material Letters, 91, 165169. doi:10.1016/j.matlet.2012.09.081
10. Tresnakova P., Horkavcova D. (2014): How the sol affects quality of optical layers containing $\mathrm{Cu}^{+}$ions. Ceramics Silikáty, 58 (3), 198-201.

11. Ajami A., Husinsky W., Svecova B., Vytykacova S., Nekvindova P. (2015): Saturable absorption of silver nanoparticles in glass for femtosecond laser pulses at 400 nm. Journal of Non-Crystalline Solids, 426, 159-163. doi:10.1016/j.jnoncrysol.2015.06.027

12. Svecova B., Varak P., Vytykacova S., Nekvindova P., Mackova A., Malinsky P., Bottger R. (2016): A study of the behaviour of copper in different types of silicate glasses implanted with $\mathrm{Cu}^{+}$and $\mathrm{O}^{+}$ions. submitted for publication in Nuclear Instruments and Methods in Physics Research B

13. Malinsky P., Mackova A., Bocan J., Svecova B., Nekvindova P. (2009): Au implantation into various types of silicate glasses. Nuclear Instruments and Methods in Physics Research, B 267, 1575-1578. doi:10.1016/j.nimb. 2009.01.161

14. Svecova B., Nekvindova P., Mackova A., Malinsky P., Kollitsch A., Machovic V., Stara S. (2010): Study of $\mathrm{Cu}^{+}$, $\mathrm{Ag}^{+}$and $\mathrm{Au}^{+}$ion implantation into silicate glasses. Journal of Non-Crystalline Solids, 356, 2468-2472. doi:10.1016/j.jnoncrysol.2010.03.031

15. Malinsky P., Mackova A., Nekvindova P., Svecova B., Kormunda M., Kolitsch A. (2011): The characterization of silicate glasses implanted with $\mathrm{Ag}^{+}$ions. AIP Conference Proceedings, 1412, 327-334. doi:10.1063/1.3665331

16. Husinsky W., Ajami A., Nekvindova P., Svecova B., Pesicka J., Janecek M. (2012): Z-scan study of nonlinear absorption of gold nano-particles prepared by ion implantation in various types of silicate glasses. Optical Communications, 285, 2729-2733. doi:10.1016/j.optcom.2012.01.044

17. Vytykacova S., Svecova B., Nekvindova P., Spirkova J., Mackova A., Miksova R., Bottger R. (2016): The formation of silver metal nanoparticles by ion implantation in silicate glasses. Nuclear Instruments and Methods in Physics Research B 371, 245-250. doi:10.1016/j.nimb.2015.10.016

18. Svecova B., Nekvindova P., Stanek S., Vytykacova S., Mackova A., Malinsky P., Miksova R., Janecek M., Pesicka J., Spirkova J. (2017): The effect of various silicate-glass matrixes on gold-nanoparticle formation. Ceramics - Silikáty, 61, 52-58. doi: 10.13168/cs.2016.0060

19. Exnar P. (2006). Metoda sol-gel. $1^{\text {st }}$ ed. Technická univerzita v Liberci. 